\title{
Correspondence
}

\section{Response to Buckle}

SIR

Stephen Buckle's insistence on the fundamental similarity of processes and events in his article Biological processes and moral events (1988; 14:144-147), for all its instructiveness, wholly misses the point of the Australian Senate Select Committee's pronouncements on the question of the proper characterisation of the process of embryonic development (1). For Dr Buckle confuses events qua biological/factual occurrences and events qua 'morally significant markers'; and although the latter are his (and the Senate Select Committee's) ultimate concern, he proposes an analogy, viz the processcum-event of kicking a football, which concerns only a factual occurrence and is thereby singularly unhelpful in illuminating the question of our proper moral concern for the embryo.

There is nothing in the Senate Select Committee's report to suggest the belief that a biological process, being continuous, excludes the possibility of there being distinct events occurring during that process, or that the process in its entirety can properly be regarded as one big event. Nor is it evident that the committee, in preparing its report, was labouring under a philosophical confusion over whether a simple event like the kicking of a football could not also be regarded, with the help of a slow-motion camera, as a process. Rather, it asserts that the very continuity of early human development, with its profound complexity and fine-tuning, features which it does not take a slow-motion camera to reveal, precludes the stipulation that any particular event within that process, such as syngamy, implantation, the development of sentience, viability, etc, should be regarded as any more morally significant than any other, at least as far as non- therapeutic experimentation and destruction are concerned. The fact that the committee concludes thus demonstrates that it is not as confused as Dr Buckle thinks about the proper characterisation of events and processes; for clearly, in denying the special moral significance of various events in the life of the early human being, and their concomitant stages, it accepts that, as a matter of fact, they obtain.

Therefore, the central argument from analogy proposed by Dr Buckle misses the point of the debate. The inference he draws from it is that, given that individuable events do obtain during early human development, the possibility is left open that some of these might be more 'morally significant' than others; his own favourite might be, say syngamy. What I claim is that his inference concerning the possibility of morally significant events should have been the premise of his argument, and that he should have been engaged in showing that there are such events, for good philosophical and empirical reasons. This is what the Senate Select Committee, in its wisdom, and after hearing much evidence, denied; and for Dr Buckle merely to gainsay its conclusion, while spuriously attributing to it an elementary conceptual confusion, is not to advance the debate.

I might add that I find Dr Buckle's 'best solution' to the 'problem' of what fertilisation is wholly implausible. Fertilisation is uncontentiously regarded by most people as the event constituted by the penetration of the ovum by the sperm. Given that penetrating the egg might take the sperm several hours, how does this licence the inference that 'fertilisation is that causal sequence beginning when the sperm succeeds in penetrating the egg, and ending when syngamy is complete' ( $p$ 145), ie fifteen days later? Dr Buckle has offered no argument for this conclusion. Indeed, he says that 'to conclude thus is, in the first place, to propose a convention to govern the proper employment of a term in our language, not to insist on an obvious matter of fact'. Moreover, such a proposal goes against the very tenor of Dr Buckle's article, with its emphasis of the point that events can be individuated even though they can often also be regarded as processes: why then should we regard the event of fertilisation as taking fifteen days simply because penetration of the ovum is not instantaneous? It seems then that it is Dr Buckle, not the Senate Select Committee, who is confused as to the inferences to be drawn from a consideration of events and processes. It is this distortion of our ordinary language and of our ordinary understanding of terms such as 'fertilisation', in order to justify certain moral ends, against which we should be vigilant.

\section{References}

(1) Senate Select Committee on the Human Embryo Experimentation Bill 1985. Human embryo experimentation in Australia. Canberra: Australian Government Publishing Service, 1986.

DAVID S ODERBERG Wolfson College Oxford, OX2 6UD

\section{To tell or not to tell the diagnosis of schizophrenia}

\section{SIR}

I find myself having to put pen to paper in reaction to Jacqueline Atkinson's paper in the Fournal of Medical Ethics March 1989, entitled To tell or not to tell the diagnosis of schizophrenia. 